\title{
PHOTOMETRY AND THE BLAZHKO EFFECT IN THE RR Lyr VARIABLE STAR Y Vul
}

\author{
S. N. Udovichenko and L. E. Keir \\ Astronomical Observatory, Odesa National University, \\ Odesa, Ukraine, udovich222@ukr.net
}

\begin{abstract}
The RR Lyr variable star Y Vul have been observed by using a CCD photometer during several seasons from 2011 to 2017 . Nearly 5960 data points were obtained spanning over 53 nights. We found the amplitude and phase modulations with the amplitudes of $0.16 \mathrm{mag}$ and 0.041 of the pulsating phase in $\mathrm{V}$ filter; $0.15 \mathrm{mag}$ and 0.041 of the pulsating phase in $\mathrm{R}$ filter, respectively. The frequency Fourier analysis of the light curves with the help of Period04 software was performed, Blazhko modulation period (59.20 days) and triplet structures in the Fourier spectrum were detected. The pulsation frequency components in the Fourier spectrum were identified up to the 7 th harmonic order, while the modulation side lobe frequencies - up to 9 th order. The analysis of the light curves maxima resulted in the same value of the Blazhko period. The fundamental pulsation period of the star has been practically stable over a period of a hundred years.
\end{abstract}

АНОТАЦІЯ. У даній роботі ми досліджуємо змінну зорю типу RR Lyr - Y Vul, яка спостерігалась нами на протязі декількох спостережних сезонів з 2011 по 2017 роки за допомогою ПЗЗ фотометра. Було одержано біля 5960 вимірювань блиску протягом 53 ночей спостережень. Ми знайшли амплітудну і фазову модуляції кривих блиску 3 амплітудою 0.16 mag i 0.041 по фазі для $\mathrm{V}$ фільтра; $0.15 \mathrm{mag} \mathrm{i}$ 0.041 по фазі для $\mathrm{R}$ фільтра, відповідно. Для всіх кривих блиску був виконаний чисельний Фур'є аналіз за допомогою відомої програми для аналізу блиску змінних зір - Period04; знайдений період модуляції кривих блиску ефект Блажко (59.20 днів) та триплетна структура Фур'є спектра. Частотні пульсаційні компоненти в Фур'є спектрі були ідентифіковані до 7 гармоніки, а модуляція в бокових пелюстках спектру - до 9 гармоніки. Аналіз моментів максимумів блиску дав аналогічний результат щодо періоду ефекта Блажко. В той же час основний фундаментальний період коливання блиску зорі був практично стабільний на протязі ста років.

Keywords: Stars: variables: RR Lyr stars - Y Vul.

\section{Introduction}

Y Vul (AN 1907.0004, Gaia DR1 - 286.0678990585, USNO-A2.0 $1125-11247385), \quad\left(\alpha_{J 2000.0}=\right.$ $\left.19^{h} 04^{m} 16.3^{s} ; \quad \delta_{J 2000.0}=+24^{\circ} 47^{\prime} 19.1^{\prime \prime}\right)$ is known as the variable star for more than hundred years, but this RRab variable has been poorly investigated. The variability of the star was explored by van Biesbroeck and Casteels (1914), and they have defined that the star belongs to RR Lyr variables. However, in spite of their detailed observations, the authors haven't deduced the light curve elements. Using observation data, reported by van Biesbroeck and Casteels, Tsesevich (1960) derived a period and epoch of Y Vul as follows:

$$
\text { MaxJD }=2419221.531+0^{d} .44941 \times E .
$$

He pointed out the difference in height of the light curves maxima and suspected the presence of the Blazhko effect in Y Vul. Using photographic observations in the range JD 2433034-41492, Kazarovets end Shugarov (1973) determined elements of the light-curve variation more accurately:

$$
\operatorname{Max} J D=2438939.413+0^{d} .44945164 \times E .
$$

Their estimated range of the light variation was $14^{m} .2-16^{m} .0(\mathrm{pg})$. The data reported in their study for $\mathrm{Y} \mathrm{Vul}$ were included to the General Catalogue of Variable Stars (GCVS) (Samus' at al. 2017) and AAVSO Variable Star Index (VSX database, https://www.aavso.org/vsx/index.php).

\section{Observations}

The photometric CCD observations of Y Vul were obtained at the Astronomical station near Odesa during the observation seasons in 2011-12, 2014-16 years in V filter; later on, in 2017 year the observations were performed in $\mathrm{R}$ filter using the $48 \mathrm{~cm}$ reflector AZT-3 of Astronomical observatory of Odessa National University, equipped with CCD photometer and Peltier cooler 
Table 1: The magnitudes of the comparison and check stars (NOMAD).

\begin{tabular}{lllll}
\hline Star & $\alpha, \delta_{2000}$ & magB & magV & magR \\
\hline comA & 190412 & 14.63 & 13.76 & 13.09 \\
& +244520 & - & - & - \\
comB & 190408 & 12.905 & 12.424 & 12.090 \\
& +244547 & - & - & - \\
check & 190415 & 14.40 & - & 14.18 \\
& +244612 & - & - & - \\
Y Vul & 190416 & 15.180 & 14.680 & 15.070 \\
& +244719 & - & - & - \\
\hline
\end{tabular}

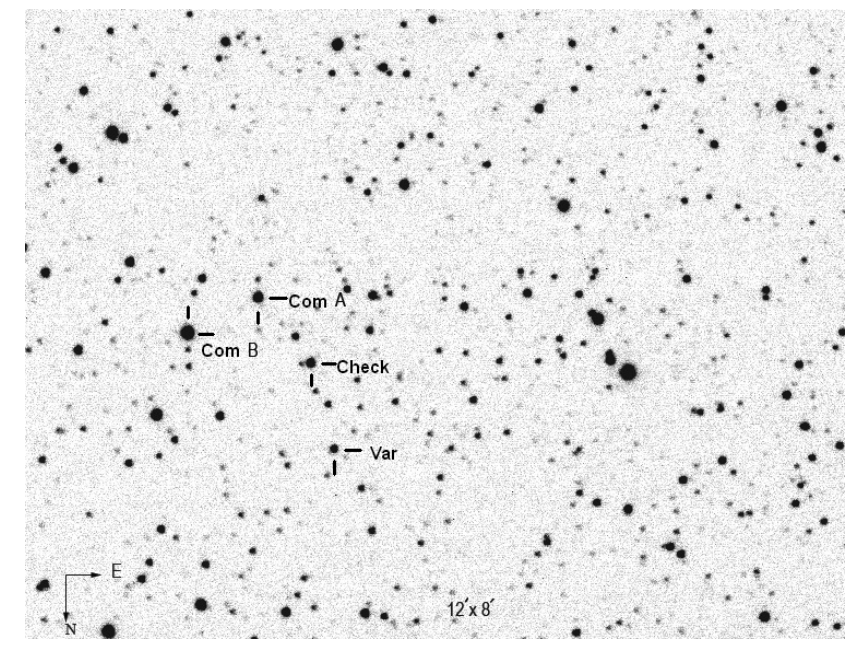

(Sony chip ICX429ALL, $\sim 600 x 800$ pixels) in the $\mathrm{f} / 4.5$ Newtonian focus (Udovichenko 2012).

The datasets consists of $4290 \mathrm{~V}$-band data points and 1665 Rc-band points obtaind from over 53 nights of observations. Two stars were chosen as comparison and one as check stars as close as possible in B-V color. The magnitude of comparison star comB we have took from NOMAD cataloque (NOMAD 2005). We accepted these magnitudes and measured star comA relative to star comB on our frames. The resulting magnitudes for star comA are: $\mathrm{V}=13.76, \mathrm{R}=13.09$ with errors of $0.02 \mathrm{mag}$. The exposure time for variable and comparison stars was chosen to except a saturation of the frame and appointed as $120 \mathrm{sec}$. The BVR magnitudes of the variable, comparison and check stars from NOMAD catalogue; are summarized in Table 2.

The standard reduction of the CCD frames were carried out by using the MUNIPACK (Motl, http://sourceforge.net/projects/c-munipack ) software. The procedures for an aperture photometry is composed of the dark-level and flat-field corrections, determination of the instrumental magnitudes and precision. The magnitude of comparison star "com A" was used to convert the differential magnitudes to the corresponding value of variable. The photometry was transformed to the standard VRc Johnson-Cousins system by means of the differential photometry method (Benson 1998). The transformation coefficient was determined from observations of standard stars (Udovichenko 2012). The finding chart with marketout variable, comparison and check stars is shown in Fig. 1, the whole dataset of observations is presented in Fig. 2. The errors in individual data points vary from $0^{m} .005$ to $0^{m} .02$.

\section{Frequency spectrum analysis}

All data on the light variation curves nearby maxima and minima have been approximated by polynoms of 2-7 degrees with the best fit option by using sowtware MCV (Andronov and Baklanov 1998). Then amplitudes of light variations and times of maxima

Figure 1: The finding chart of Y Vul with the variable, comparison and check stars marked.

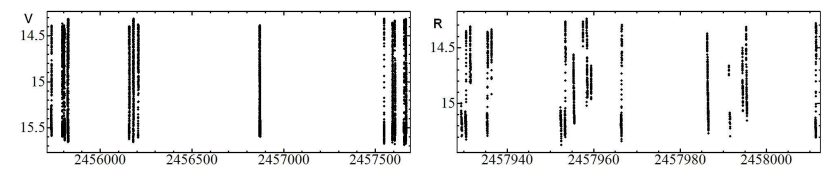

Figure 2: The all data set of observations of Y Vul.

have been defined. The observations of Y Vul shows the whole amplitude variation $1^{m} .05$ in Rc-band and $1^{m} .33$ in V-band. The modulation occurs at the maximum brightness and phase shift too. The brightness at maxima of the light curves in Rc-band vary from $14^{m} .265$ to $14^{m} .411$, the moderate Blazhko modulation of the amplitude reaches about 0.146; in V-band vary from $14^{m} .316$ to $14^{m} .478$, and the modulation reaches $0^{m} .162$. The phase shift modulation in both bands varies within about 0.041 of the pulsation phase. All light curves of the target star obtained by using $\mathrm{V}$ and Rc filters with the pulsating period, are shown on Fig. 3. These phase curves were computed by using GCVS elements, equation 2.

To analyse the modulation properties of the light curves for this star, we have used a common technique a Fourier decomposition. The frequency analysis was performed using a package of computer programs with sine-wave fitting by using utilize Fourier algorithms (program Period04), (Lenz and Breger 2005).

To capture longer time interval, we calculated observations, obtained with V-band and Rc-band.

The fundamental pulsation period was determined with the help of using the above-mentioned techniques as the highest peak on the Fourier amplitude spectrum. The observed harmonics and triplet were defined by pre-whitening data and Fourier analysis of the residuals. For each calculated harmonic and triplet, the signal-to-noise ratio has been estimated to retain only 

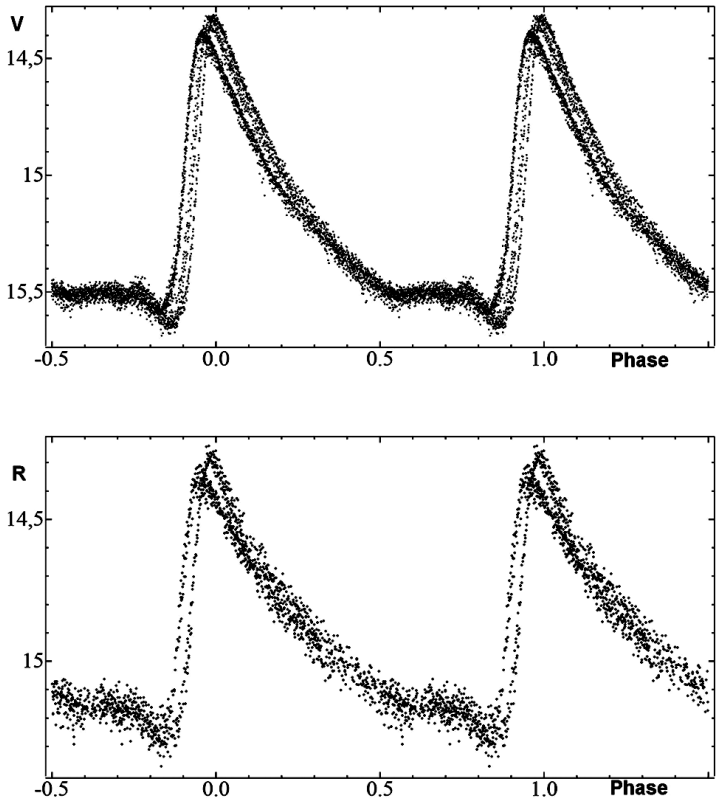

Figure 3: The phase curves of Y Vul in V and Rc filters.

significant signals greater than 4 . The amplitude and phase for each frequencies, obtained with the best fitting, are given in Table 2 .

The amplitude spectrum for the basic pulsating frequency and after pre-whitening are shown in Fig. 4. The harmonics of $\mathrm{f}_{0}$ are significant to the $7^{\text {th }}$ order, triplets $\mathrm{f}_{0} \pm \mathrm{f}_{m}$ to $9^{\text {th }}$ order. The fundamental pulsating period $\mathrm{P}_{0}=0.44945177$ is very close to the GCVS value. The Blazhko frequency also was determined as the difference of frequencies $\mathrm{f}_{m}=\mathrm{kf}_{0}-\mathrm{kf}_{0} \pm \mathrm{f}_{m}$ and given in the last column of Table 2. Some of these frequencies contains an alias frequencies $\sim(1 / 365=0.0027)$ as a result of the several seasons of observations (201117). Keeping that in mind we only used non-aliased frequencies to determine the Blazhko frequency. The average value equals $0.01689 \pm 0.0004 \mathrm{~cd}^{-1}$, whith corresponds to the period of $59.20 \pm 0.14$ day.

The amplitude asymmetry is observed in the modulation components: $Q_{i}=\left(A_{i 1}^{+}-A_{i 1}^{-}\right) /\left(A_{i 1}^{+}+A_{i 1}^{-}\right)$, where $A_{i 1}^{+}=$if $_{0}+\mathrm{f}_{m}, A_{i 1}^{-}=$if $_{0}-\mathrm{f}_{m}$. The asymmetry ratios for the first component $Q_{1}=0.36$; the triplet ratios in the side lobes $R_{1}=A_{11}^{+} / A_{11}^{-}=2.16$. The amplitudes of the pulsation components which decrease with increasing orders are smooth while the amplitudes of the modulation components decrease irregularly.

\section{Light curves maxima analysis}

The times of maxima in the all light curves was performed with help of fitting the light curve near the maxima by a polynomial function an order from 2 to 7 . The list of observed light curves maxima presents in Ta-
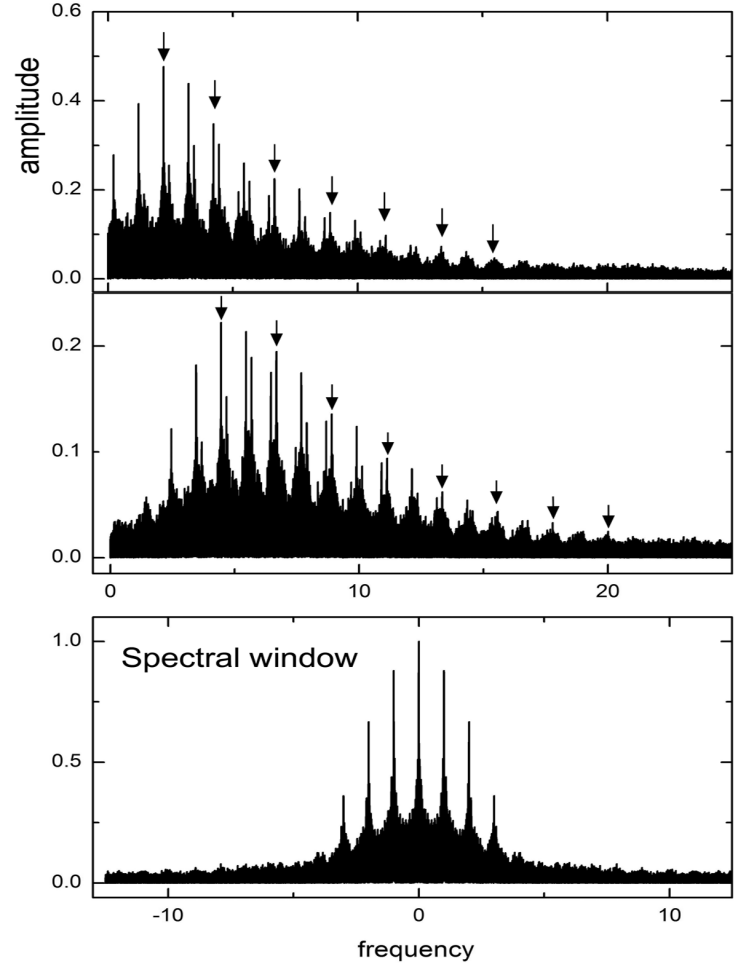

Figure 4: The Fourier amplitude spectrum of the basic frequency and after the first pre-whitening. In the above figure the arrows point to the basic pulsation frequency and its harmonics $\mathrm{kf}_{0}$. In the middle figure the arrows point to the modulation frequency triplets $\mathrm{kf}_{0} \pm \mathrm{f}_{m}$ after the next pre-whitening. The bottom figure shows the spectral window.

ble 3. The modulation Blazhko period was determined by the (O-C) period analysis (using Period04). The both method (i.e. frequency spectrum analysis and (O-C) deviation at maximum) have shown the same value of a Blazhko period. The value from the light curves maxima analysis equal $59.20 \pm 0.02$ days. We selected the highest observed maximum and derived the elements of the Blazhko cycle:

$$
\text { MaxHJD } D_{\text {Blazhko }}=2457548.505+59^{d} .20 \times E_{\text {Blazhko }}
$$

The O-C diagram of Y Vul versus the Blazhko phase with sinusoidal fitting curve is presented in Fig. 5 (top). The O-C values are different in $9 \%$ of the pulsation period, the magnitudes at maximuma are different in $12-14 \%$ of the $\mathrm{V}$ and Rc amplitude.

The O-C diagram was constructed by using all the published observational data available (Tsessevich 1960; Kazarovets and Shugarov 1973) as well as the data, obtained in this study by using the GCVS elements. The resulting diagram with linear fit is plotted in Fig. 5 (bottom). The data covers the 
Table 2: Identify frequencies, amplitudes, phases and modulation frequencies $\mathrm{f}_{m}=\mathrm{kf}_{0}-\mathrm{kf}_{0} \pm \mathrm{f}_{m}$ of the $\mathrm{V}$ and Rc light curve solutions of Y Vul.

\begin{tabular}{|c|c|c|c|c|c|}
\hline Identification & $\mathbf{f}\left(\mathbf{c d}^{-1}\right)$ & amplitude, mag & phase, $\mathrm{rad} / 2 \pi$ & snr & $\mathbf{f}_{m}\left(\mathbf{c d}^{-1}\right)$ \\
\hline & & \multicolumn{4}{|l|}{ V-band } \\
\hline $\mathrm{f}_{0}$ & $2.224936(2)$ & $0.311(1)$ & $0.084(1)$ & 94.2 & \\
\hline $2 \mathrm{f}_{0}$ & $4.449874(3)$ & $0.187(2)$ & $0.303(2)$ & 35.2 & \\
\hline $3 \mathrm{f}_{0}$ & $6.674817(3)$ & $0.160(1)$ & $0.845(2)$ & 31.4 & \\
\hline $4 \mathrm{f}_{0}$ & $8.899735(3)$ & $0.100(2)$ & $0.203(3)$ & 22.1 & \\
\hline $5 f_{0}$ & $11.12464(1)$ & $0.050(4)$ & $0.63(1)$ & 13.5 & \\
\hline $7 \mathrm{f}_{0}$ & $15.5717(6)$ & $0.029(8)$ & $0.06(2)$ & 9.2 & \\
\hline $\mathrm{f}_{0}+\mathrm{f}_{m}$ & $2.24188(3)$ & $0.031(9)$ & $0.07(1)$ & 7.1 & $0.01694(3)$ \\
\hline $\mathrm{f}_{0}-\mathrm{f}_{m}$ & $2.20803(6)$ & $0.027(8)$ & $0.3(3)$ & 6.7 & $0.01691(6)$ \\
\hline $2 \mathrm{f}_{0}-\mathrm{f}_{m}$ & $4.433004(9)$ & $0.051(2)$ & $0.268(7)$ & 5.6 & $0.01687(1)$ \\
\hline $3 \mathrm{f}_{0}+\mathrm{f}_{m}$ & $6.691688(7)$ & $0.046(2)$ & $0.088(6)$ & 9.3 & $0.01688(1)$ \\
\hline $4 \mathrm{f}_{0}+\mathrm{f}_{m}$ & $8.91661(1)$ & $0.040(2)$ & $0.952(9)$ & 9.5 & $0.01687(1)$ \\
\hline $6 \mathrm{f}_{0}-\mathrm{f}_{m}$ & $13.33284(5)$ & $0.038(9)$ & $0.009(3)$ & 11.4 & $0.01678(5)$ \\
\hline $7 \mathrm{f}_{0}+\mathrm{f}_{m}$ & $15.59158(2)$ & $0.018(3)$ & $0.71(3)$ & 4.5 & $0.01702(2)$ \\
\hline $8 \mathrm{f}_{0}-\mathrm{f}_{m}$ & $17.78265(1)$ & $0.017(2)$ & $0.71(2)$ & 4.0 & $0.01684(1)$ \\
\hline \multirow[t]{2}{*}{$9 \mathrm{f}_{0}+\mathrm{f}_{m}$} & $20.0076(1)$ & $0.09(1)$ & $0.7(3)$ & 7.2 & $0.0168(1)$ \\
\hline & & R-band & & & \\
\hline $\mathrm{f}_{0}$ & $2.22491(6)$ & $0.432(4)$ & $0.992(2)$ & 56.2 & \\
\hline $2 \mathrm{f}_{0}$ & $4.4497(1)$ & $0.152(3)$ & $0.715(8)$ & 36.6 & \\
\hline $3 f_{0}$ & $6.6744(4)$ & $0.105(2)$ & $0.415(4)$ & 27.5 & \\
\hline $4 f_{0}$ & $8.8994(4)$ & $0.073(4)$ & $0.813(8)$ & 16.2 & \\
\hline $5 f_{0}$ & $11.1235(7)$ & $0.043(6)$ & $0.62(2)$ & 13.0 & \\
\hline $6 f_{0}$ & $13.50(6)$ & $0.022(8)$ & $0.9(3)$ & 5.0 & \\
\hline $7 f_{0}$ & $15.575(1)$ & $0.021(3)$ & $0.19(1)$ & 5.0 & \\
\hline $\mathrm{f}_{0}-\mathrm{f}_{m}$ & $2.2094(3)$ & $0.038(4)$ & $0.17(1)$ & 6.9 & $0.0151(3)$ \\
\hline $2 \mathrm{f}_{0}+\mathrm{f}_{m}$ & $4.465(4)$ & $0.035(9)$ & $0.9(3)$ & 8.4 & $0.015(4)$ \\
\hline $3 \mathrm{f}_{0}-\mathrm{f}_{m}$ & $6.659(2)$ & $0.037(8)$ & $0.7(1)$ & 9.6 & $0.016(2)$ \\
\hline $4 \mathrm{f}_{0}+\mathrm{f}_{m}$ & $8.916(4)$ & $0.038(3)$ & $0.30(1)$ & 8.4 & $0.016(4)$ \\
\hline $5 \mathrm{f}_{0}-\mathrm{f}_{m}$ & $11.109(2)$ & $0.028(9)$ & $0.6(1)$ & 8.3 & $0.016(2)$ \\
\hline $8 \mathrm{f}_{0}-\mathrm{f}_{m}$ & $17.782(4)$ & $0.016(3)$ & $0.4(1)$ & 4.6 & $0.017(4)$ \\
\hline
\end{tabular}

period of a hundred years. The O-C difference over such long period less than 0.02 day, which is less than the Blazhko phase change. It allows to assume, that Y Vul has practically no secular period changes. The scattering of dots is due to the Blazhko effect.

\section{Conclusions}

This paper describes the modulation of the light curves of a RR Lyrae variable Y Vul. Using the data obtained from the several observational seasons, we have found the Blazhko effect for the pulsating in the fundamental mode. The amplitude of the maximum brightness variation reaches $0^{m} .162$ with $\mathrm{V}$ filter and $0^{m} .146$ in Rc filter; the phase shift is 0.041 of pulsation phase. Using the Fourier analysis for these data we have derived the fundamental pulsating period of $0.4494517 \pm 0.000001$ day. The Blazhko period was defined using the $\mathrm{O}-\mathrm{C}$ value at maxima and frequency spectrum analysis. The average period equal $59.20 \pm$ 0.02 days. The modulation of the $\mathrm{Y}$ Vul light curves are described by the triplet frequencies $\mathrm{kf}_{0} \pm \mathrm{f}_{m}$ and the modulation frequency $\mathrm{f}_{m}$. In the frequency spectrum
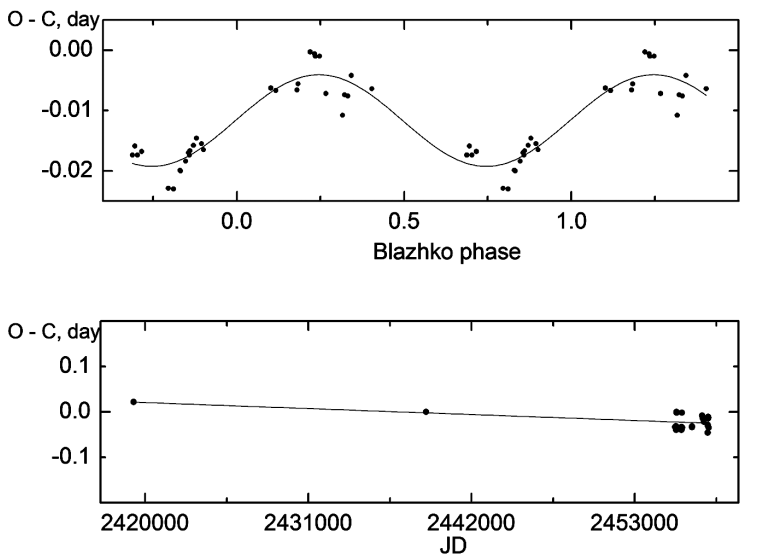

Figure 5: The O-C (day) diagram of Y Vul versus Blazhko phase with the sinusoidal fitting curve (top figure). The O-C (day) diagram of Y Vul during over a hundred years with the linear fitting (bottom figure). 
Table 3: List of measured maxima of Y Vul

\begin{tabular}{|c|c|c|c|c|c|c|c|c|}
\hline Maximum HJD & Error & Magnitude (V-C) & Error & Cycle & $\mathrm{O}-\mathrm{C}$ & Phase & Error & Filter \\
\hline 2455735.4040 & 0.00019 & 0.6209 & 0.0028 & 37369 & -0.0168 & -0.0374 & 0.0004 & $\mathrm{~V}$ \\
\hline 2455793.3841 & 0.00021 & 0.6288 & 0.0027 & 37498 & -0.0159 & -0.0354 & 0.0004 & V \\
\hline 2455801.4702 & 0.00025 & 0.6499 & 0.0034 & 37516 & -0.0199 & -0.0444 & 0.0005 & $\mathrm{~V}$ \\
\hline 2455802.3706 & 0.00018 & 0.6315 & 0.0027 & 37518 & -0.0184 & -0.0410 & 0.0003 & $\mathrm{~V}$ \\
\hline 2455805.5187 & 0.00071 & 0.6752 & 0.0112 & 37525 & -0.0165 & -0.0367 & 0.0015 & $\mathrm{~V}$ \\
\hline 2455824.4119 & 0.00028 & 0.5622 & 0.0049 & 37567 & -0.0002 & -0.0006 & 0.0006 & V \\
\hline 2455825.3101 & 0.00023 & 0.5534 & 0.0034 & 37569 & -0.0010 & -0.0022 & 0.0005 & $\mathrm{~V}$ \\
\hline 2456156.5371 & 0.00031 & 0.6479 & 0.0034 & 38306 & -0.0198 & -0.0442 & 0.0007 & V \\
\hline 2456158.3380 & 0.00023 & 0.6349 & 0.0030 & 38310 & -0.0167 & -0.0372 & 0.0005 & $\mathrm{~V}$ \\
\hline 2456180.3773 & 0.00020 & 0.5633 & 0.0033 & 38359 & -0.0006 & -0.0013 & 0.0004 & V \\
\hline 2456181.2759 & 0.00026 & 0.5609 & 0.0041 & 38361 & -0.0009 & -0.0021 & 0.0005 & V \\
\hline 2456207.3276 & 0.00048 & 0.6349 & 0.0055 & 38419 & -0.0174 & -0.0387 & 0.0010 & V \\
\hline 2456208.2265 & 0.00024 & 0.6276 & 0.0021 & 38421 & -0.0174 & -0.0387 & 0.0005 & V \\
\hline 2456868.4714 & 0.00023 & 0.6360 & 0.0030 & 39890 & -0.0169 & -0.0377 & 0.0005 & V \\
\hline 2456869.3714 & 0.00022 & 0.6290 & 0.0029 & 39892 & -0.0158 & -0.0352 & 0.0005 & V \\
\hline 2457548.5045 & 0.00027 & 0.5528 & 0.0048 & 41403 & -0.0041 & -0.0092 & 0.0006 & V \\
\hline 2457593.4476 & 0.00031 & 0.6061 & 0.0040 & 41503 & -0.0063 & -0.0140 & 0.0007 & V \\
\hline 2457594.3460 & 0.00030 & 0.6009 & 0.0050 & 41505 & -0.0067 & -0.0150 & 0.0006 & V \\
\hline 2457606.4806 & 0.00022 & 0.5664 & 0.0027 & 41532 & -0.0073 & -0.0163 & 0.0004 & V \\
\hline 2457657.2694 & 0.00028 & 0.5710 & 0.0045 & 41645 & -0.0066 & -0.0147 & 0.0006 & V \\
\hline 2457665.3550 & 0.00029 & 0.5695 & 0.0044 & 41663 & -0.0111 & -0.0248 & 0.0006 & V \\
\hline 2457666.2574 & 0.00040 & 0.5599 & 0.0069 & 41665 & -0.0076 & -0.0169 & 0.0009 & V \\
\hline 2457899.5228 & 0.00043 & 0.5565 & 0.0078 & 42184 & -0.0076 & -0.0170 & 0.0010 & V \\
\hline 2457930.5197 & 0.00033 & 1.2740 & 0.0062 & 42253 & -0.0229 & -0.0509 & 0.0007 & $\mathrm{R}$ \\
\hline 2457931.4185 & 0.00038 & 1.2249 & 0.0043 & 42255 & -0.0229 & -0.0510 & 0.0008 & $\mathrm{R}$ \\
\hline 2457935.4719 & 0.00051 & 1.2772 & 0.0060 & 42264 & -0.0146 & -0.0325 & 0.0011 & $\mathrm{R}$ \\
\hline 2457936.3699 & 0.00073 & 1.2768 & 0.0075 & 42266 & -0.0155 & -0.0345 & 0.0016 & $\mathrm{R}$ \\
\hline 2457953.4590 & 0.00034 & 1.1902 & 0.0054 & 42304 & -0.0055 & -0.0124 & 0.0007 & $\mathrm{R}$ \\
\hline 2457958.4014 & 0.00070 & 1.1700 & 0.0064 & 42315 & -0.0071 & -0.0159 & 0.0015 & $\mathrm{R}$ \\
\hline 2457966.4924 & 0.00036 & 1.1909 & 0.0074 & 42333 & -0.0063 & -0.0141 & 0.0008 & $\mathrm{R}$ \\
\hline 2457993.4484 & 0.00066 & 1.2576 & 0.0089 & 42393 & -0.0174 & -0.0388 & 0.0014 & $\mathrm{R}$ \\
\hline
\end{tabular}

the pulsation harmonic components are detected up to the $7^{\text {th }}$ order; the modulation side lobe frequencies are detected up to $9^{\text {th }}$ order. Thirty pulsation maxima from the observed light curves have been measured. The fundamental pulsation period of the star has been practically stable over a period of a hundred years.

\section{References}

Andronov, I.L., Baklanov, A.V.: 2004, Astronomical School's Report, 5, 264.

Benson, P.J.: 1998, Intern. Amateur-Professional Photoel. Photom. Communic., 72, 42.

Blazhko, S., Mitteilung uber veranderliche Sterne: 1907, AN, 175, 325.

Kazarovets, E. V., Shugarov, S. Y., 1973, Peremennye Zvezdy Prilozhenie, 1, 455.
Lenz P., Breger M.: 2004, Comm. in Asteroseismology, 146, 53.

Samus N.N., Durlevich O.V., Kazarovets E V., Kireeva N.N., Pastukhova E.N., Zharova A.V. et al.: 2011, General Catalogue of Variable Stars (GCVS database, Version 2011Jan).

Tsesevich V.P.: 1960, Astronomicheskij Tsirkulyar, 215, 24.

Udovichenko S.N.:2012, Odessa Astron. Publ., 25, 32. van Biesbroeck, G., Casteels, L.: 1914, Annales de l'Observatoire Royal de Belgique Nouvelle serie, 13.

Zacharias N. et al.: 2005, VizieR Online Data Catalog: NOMAD Catalog (Zacharias+2005), 1297. 